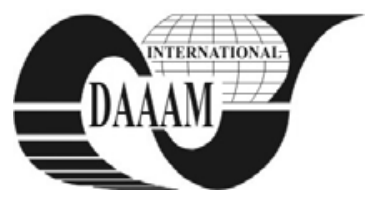

\title{
DEMAND-CONTROLLED AIR VENTILATION STRATEGIES AND HEAT TRANSFER IN BUILDING AUTOMATION
}

\author{
TEICH, T[obias]; SZENDREI, D[anny]; FRANKE, S[usan] \& LEONHARDT, S[ven]
}

\begin{abstract}
Improving building standards and facility services in residential buildings is one major effort for future energy savings. Due to current facility standards and tightened legal restrictions, automated air ventilation (AVS) can contribute large potentials towards energy consumption downsizing. Current legal efforts (EnEV) enforce facility services to maintain high indoor air quality (IAQ) without natural air ventilation possibilieties, such as gap ventilation (Paessler, 2010). Aiming at heat loss avoidance in residential buildings, heat loads in different ventilation zones are used for heat transfer via AVS with heat recovery components.Therefor, the required ventilation stategy distinguishes supply and extract air zones and highlights local heat utilization. In this paper the effort of transferring heat from intermediate high temperature level zones (IHTLin extract air zones), such as bathrooms and kitchens into long term medium temperature level zones (LMTL in supply air zones) by using air ventilation systems with heat recovery is presented. Multiple control variables (air quality, humidity, temperature and presense information) are presented as demand indicators fir indoor air quality. Furthermore, the building automation infrastructure for sensoring and processing IAQas well as thermal utilisation is introduced.

Key words: automated air ventilation, demand control, building automation, energy-efficiency, heat transfer
\end{abstract}

\section{INTRODUCTION}

About $70 \%$ of the overall energy consumption in Europe accounts for space heating and household appliances (Szendrei, 2010). Significantly, the share of energy demand for air and hygiene ventilation of currently about $40 \%$ is expected to rise, due to building physics and health requirements in residential buildings (Laverge et.al., 2011). So far, most facilities services in residential buildings are planned, installed, operated and maintained by different crafts (Teich et.al., 2010). With the development of building automation standards, such as the KNX-standard (Konnex), an integrative facility management for those various crafts and facilities services can be deployed. KNX-technology enables controlling local networks in a variety of functions (air ventilation, power distribution, heating control, security installation and others) on the platform of the European Installation Bus (EIB). An IP backbone within residential buildings interconnects all necessary sensors, actuators and controllers. That way, all essential information for mainaining proper thermal comfort are available from a single information environment.

The predicted mean vote (PMV) expresses the overall thermal comfort for humans within dwellings. Main parameters for PMV regarding air ventilation and space heating are: relative air velocity, operative air temperature and average radiation temperature (Joppich et.al., 2010). Still, one major issue of comfort that is not covered in PMV, is IAQ. The most important parameter for that term is the carbon dioxide $\left(\mathrm{CO}_{2}\right)$ concentration. It mainly influences health (sick building syndrome) as well as building physics (mould generation) conditions (Paessler, 2010; Joudis, 2005). Since the current values of this parameter are available by sensoring the rooms, it can be used for IAQ-management as well as heat transfer.

\section{HEAT TRANSFER}

\subsection{Thermal Utilization In Residential Buildings}

Energy consumption, especially heat energy utilization in residential buildings, is heterogeous, due to users preferences and habbits (Baopin et.al., 2009). On the platform of the KNXautomation bus infrastructure, some main characteristics on thermal utilization could be found. The temperature settings for space heating within the various rooms show general trends that can be used for energetic optimization with air ventilation.

\begin{tabular}{|l|l|l|l|}
\hline \multicolumn{1}{|c|}{ room } & $\begin{array}{c}\text { set- } \\
\text { temperature } \\
\text { (max) }\end{array}$ & $\begin{array}{c}\text { temperature } \\
\text { change }\end{array}$ & $\begin{array}{c}\text { utilization } \\
\text { duration }\end{array}$ \\
\hline living- & 22 & $<5 \mathrm{~K}$ & $>2 \mathrm{hrs}$ \\
\hline bed- & 17,5 & $<3 \mathrm{~K}$ & $>2 \mathrm{hrs}$ \\
\hline study/child- & 21 & $<3 \mathrm{~K}$ & $>2 \mathrm{hrs}$ \\
\hline kitchen & 22,5 & $>4 \mathrm{~K}$ & $<2 \mathrm{hrs}$ \\
\hline Bath- & 24 & $>4 \mathrm{~K}$ & $>1 \mathrm{hr}$ \\
\hline
\end{tabular}

Tab. 1. Characteristics of thermal utilisation

Regarding the presented characteristics, the various rooms can be categorized into intermediate high temperature level zones (IHTL): kitchen and bathrooms; and long term medium temperature level zones (LMTL): bedrooms, living rooms, study/child. According to:

$$
\frac{d U}{d t}=\dot{Q}=\dot{Q}_{t r}+\dot{Q}_{l}+\dot{Q}_{R H}+\dot{Q}_{i n t}+\dot{Q}_{s o l}
$$

the thermal capacity of IHTL is higher that the LMTL's heat capacity. Significant disparities are caused by inner gains, such as shower/hot tub use ore kitchen appliances in IHTL. Furthermore, the energy in IHTL is needed for only a short period of time, while most (heat) energy is lost by transmission losses over building components. These losses can used to generate inner gain within other rooms. That way, the energy effort for LMTL heat up can be downsised.

\subsection{Air Ventilation Strategy}

As technical components for heat transfer from IHTL to LMTL, air ventilation systems with heat recovery are to operate. Regarding the heat recovery effectiveness:

$$
\Phi_{\mathrm{r}}=\frac{\mathrm{t}_{\mathrm{exh}}-\mathrm{t}_{\mathrm{ex}}}{\mathrm{texh}_{\mathrm{exh}}-\mathrm{t}_{\mathrm{fr}}}
$$

the heat content of the exhausted air can be recovered to insert pre-heated delivery air of high quality. As a reference building model, a dwelling with the following characteristics is presented: 


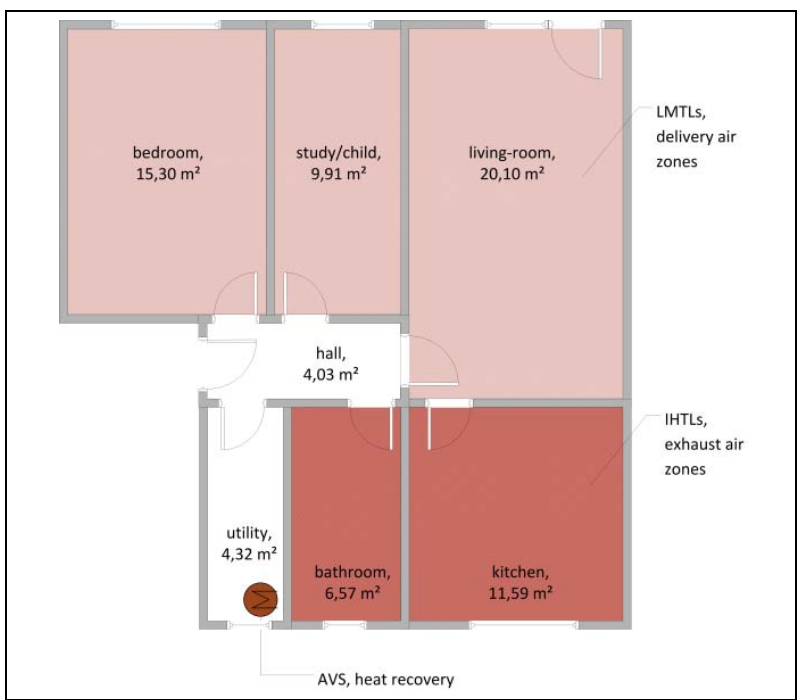

Fig. 1. Air- and thermal zones in reference dwelling

As required by DIN EN 1946 (6), the air ventilation strategy offers delivery air for LMTLs, which is pre-heated by exhaust air from IHTLs. Regarding the dwellings size, air flow rates of 80 to $120 \mathrm{~m}^{3} / \mathrm{h}$ have to be ventilated. Mechanical, automated ventilation offers demand-triggerd air supply at low energy consumption. Due to the presented flow rates, a complete air-exchange can be achieved within 90 minutes. Since a static quality improvement of indoor air does not need full air exchange, low flow rates ensure thermal comfort at minimum electrical power.

\subsection{Demand Control}

Regarding a high level of thermal comfort and IAQ, AVS are to be triggered by demand. Especially moist room usage disables high air flow rates while the room is occupied. Most common AVS use only singlular air quality indices for triggering (Fernandez et.al., 2010). In most cases the carbon dioxide $\left(\mathrm{CO}_{2}\right)$ content is implemented for system control. This is partially caused by the installation effort. While conventional sensor setups require different wiring, current bus structures (KNX) offer various applications over a single cable. Thus, economical considerations of facility management could be faced (Verbeeck et.al., 2005). The various information objects within building automation bus structures enable monitoring of multiple air quality criteria such as $\mathrm{CO} 2$, humidity, air temperature. In the reference dwelling, carbon-dioxide, relative humidity and occupancy are implemented as demand triggers. These triggers sample duration and luminosity of the ventilator motors. That way, dynamic sample schemes are implemented (Wong et.al., 2007). By monitoring the presence-status of each room, demand controlled air supply can be supplied, while the PMV indices are enhanced. The separation of exhaust and supply air zones, that correspond with thermal zones, enable transfering obsolete heat energy. Space heating in all rooms is performed by warm water heating devices according to:

$$
\dot{Q}=k * A * \Delta \vartheta_{m} .
$$

Effecting the required heat-up energy of the room expressed by:

$$
\dot{Q}_{R H}=A_{N} * f_{R H}
$$

the heat-up factor $f_{\mathrm{RH}}$ can be reduced as subject to the presented heat recovery effectiveness $\Phi_{\mathrm{r}}$.

Since the parameters of the heating device remain static, the surplus of heat energy, supplied by the heat recovery system for the LMTL, offers a more efficient heat-up (RH) phase of the corresponding LMTL, as presented in equation 1 . Thus the parameters medium temperature $\Delta \vartheta_{m}$, heating device face $A_{N}$ or the required heat-up duration can be decreased.

\section{RESULTS}

As an experimental setup, four equal dwellings in a residential building have been equipped with building automation infrastructures and AVS. For presence and utilization purposes, the electric and thermal profiles of the rooms within the dwelling have been monitored empirically. A temperature level difference between three and six Kelvin within IHTL was a finding that enabled heat transfer calculations. The obsolete heat energy, caused by individual IHTL utilization, supports the heat-up precess in LMTL. As triggers, multiple variables $\mathrm{CO}_{2}$, humidity and presence are implemented in the control algorithm. All required information on air quality conditions are gathered by corresponding sensors. In IHTL, humidity sensors and in LMTL $\mathrm{CO}_{2}$ sensors ensure proper and healthy quality criteria, especially meeting the diverse utilistaion requirements. Presence detection in moist rooms pretends users from uncomfortable air drafts. Immediate ventilation assures low electrical power consumption of the AVS, because ventilation duration can be kept short. Detailed monitoring and analysis of space heating savings are to be conducted in the oncoming heating season. The installation costs of the required components could be decreased in comparison to conventional wiring. The building automation bus finally enables integration of AVS into the holistic energy management of space heating.

\section{REFERENCES}

Baopin,X.; Fu, L. \& Hongfa, D. (2009). Field investigation on consumer behavior and hydraulic performance of a district heating system in Tianjin, China. Building and Environment, Vol. 44, Issue 2, 249-259, ISSN 0360-1323

Joppich, M. \& Lindner, K. (2010). Energieoptimierte Lüftung unter Berücksichtigung der Raumluftqualität. In: Energieeffizienz in Wohngebäuden, Teich T; Igel W. (Ed.), 171-180, GUC Verlag, ISBN: 978-3-934235-89-2, Chemnitz

Pässler, C. (2010). Wohnungsbelüftung. Stand der Technik und Tendenzen. VDM Verlag, ISBN 978-3639273397, Saarbrücken

Fernández-Seara, J., Diz, R., Uhía, F.J., Dopazo, A., Ferro J.M. (2011). Experimental analysis of an air-to-air heat recovery unit for balanced ventilation systems in residential buildings. Energy Conversion and Management, Vol. 52, Issue 1, 635-640, ISSN 0196-8904

Laverge, J., Van den Bossche, N., Heijmans, N. \& Janssens, A. (2011). Energy saving potential and repercussions on indoor air quality of demand controlled residential ventilation strategies. Building and Environment, Vol 46, Issue 7, 1497-1503 ISSN 0360-1323

Szendrei, D. (2011). Feasibility of integrating heating valve drivers with KNX-standard for performing dynamic hydraulic balance in domestic buildings. Proceedings of World Academy of Science, Engineering And Technology.International Conference on Electrical Power and Energy Systems 2011, Dubai, VAE, eISSN 2010-3778

Teich, T., Zimmermann, M. and Other. (2010). Intelligent Building Automation. In Karras, D.A., Moustafa K.A.F., Tang, D. (ed.), International Conference on Automation, Robotics and Control Systems. 53 - 57. ISRST. Orlando, Florida

Verbeeck, G., Hens, H. 2005. Energy savings in retrofitted dwellings: economically viable? Energy and Buildings, Vol.37, Issue 2, 747-754, ISSN 0360-1323

Wong, L.T. \& Mui, K.W.(2007). Evaluation on four sampling schemes for assessing indoor air quality. Building and Environment, Vol. 42, Issue 3, 1119-1125, ISSN 03601323 